\title{
(2) OPEN ACCESS \\ Effects of physical fitness training on metabolic syndrome among military personnel in Taiwan
}

\author{
Che-Fu Chang, ${ }^{1,2}$ Y-C Wu, ${ }^{1}$ C-H Lai, ${ }^{3}$ P-C Chen, ${ }^{1}$ Y-L Guo ${ }^{2}$
}

\begin{abstract}
- Additional material is published online only. To view, please visit the journal online (http://dx.doi.org/10.1136/ bmjmilitary-2020-001761).
\end{abstract}

${ }^{1}$ Department of Family Medicine, Taoyuan Armed Forces General Hospital, Taoyuan, Taiwan Institution of Environmenta and Occupational Health Sciences, National Taiwan University College of Public Health, Taipei, Taiwan

${ }^{3}$ Department of Public Health, National Defense Medical

Center, Taipei, Taiwan

\section{Correspondence to} Professor Y-L Guo, National Taiwan University College of Public Health, Taipei 10055

Taiwan; leonguo@ntu.edu.tw

Received 27 December 2020 Revised 20 January 2021 Accepted 21 January 2021

\section{Check for updates}

(C) Author(s) (or their employer(s)) 2021. Re-use permitted under CC BY-NC. No commercial re-use. See rights and permissions. Published by BMJ.

To cite: Chang C-F, Wu Y-C, Lai C-H, et al. BMJ Mil Health Epub ahead of print: [please include Day Month Year]. doi:10.1136/

bmimilitary-2020-001761

\section{ABSTRACT}

Introduction Metabolic syndrome (MS) is strongly associated with cardiovascular diseases and diabetes but can be prevented with regular physical activity. This study aimed to assess the impact of a physical fitness training programme on MS among military personnel.

Methods This retrospective observational study included volunteer army soldiers who underwent annual health examinations between 2011 and 2014. In 2011, the reformed physical fitness training programme and physical fitness test were introduced to the participants. MS evaluation and physical fitness performances were evaluated before and after implementing the training programme using a mixed-effects model and generalised estimating equation, adjusted for sex, age and smoking.

Results From 2011 to 2014, 1720 soldiers underwent the annual health examination. In 2011, before the fitness programme, 246 soldiers (14.3\%) had MS. After implementation, decreases in blood pressure and fasting glucose levels were observed and maintained for 3 years. Running performance was negatively correlated to triglycerides $(B=-11.37 ; p<0.001)$ and waist circumference ( $B=-0.42 ; p<0.001)$ and positively correlated to highdensity lipoprotein cholesterol levels $(B=2.14 ; p<0.001)$. The severity of MS was reduced following introduction of the physical fitness programme.

Conclusions MS and its components improved after introducing the reformed fitness programme, with running performance proving to be most relevant to MS. Clinicians should encourage increased physical activity to prevent MS among military personnel.

\section{INTRODUCTION}

Metabolic syndrome (MS) was first understood and reported to be related to insulin resistance in 1988. ${ }^{1}$ In 1990, the WHO defined the syndrome and the metabolic abnormalities involved, including insulin resistance, central obesity, hyperlipidaemia, hypertension and other cardiovascular disease risk factors. ${ }^{2}{ }^{3}$ Subsequently, the US National Heart, Lung, and Blood Institute proposed the National Cholesterol Education Program's Adult Treatment Panel III in accordance with a clinical study, examining the risk factors and blood lipid concentration standards, to further reinforce the involvement of multiple risk factors and the importance of primary and secondary prevention (Expert Panel on Detection, Evaluation, and Treatment of High Blood Cholesterol in Adults 2001). ${ }^{4}$ Moderate to vigorous physical activity has been shown to reduce risk factors for MS, whereas a sedentary lifestyle is associated with a higher incidence of MS. ${ }^{5} 6$ Despite the general belief that military service jobs

\section{Key messages}

This retrospective cohort study determined whether the physical fitness programme improved the health status of military personnel.

- This study makes a significant contribution to the literature because we used a physical fitness test to quantify the effects of cardiorespiratory fitness training.

- Results showed that running performance had a significantly negative association with waist circumference, triglyceride levels, fasting glucose and a positive association with highdensity lipoprotein cholesterol.

- Clinicians should encourage increased physical activity to prevent metabolic syndrome among military personnel.

are physically demanding, the estimated prevalence of MS in the military is $21 \%$ globally, and surprisingly, some cardiometabolic risk factors are higher in this population than in the general population. The impact of physical training on the occurrence of MS in military populations has not been well investigated.

It is generally recognised and accepted that military duties require high levels of physical fitness and performance. $^{8}$ In Taiwan, all military personnel on active duty are required to undergo basic physical training to ensure soldiers' physical fitness. Performance in the annual physical fitness test (PFT) is considered in evaluating military personnel for promotion. In the past, basic physical fitness training involved autonomous training, and there were no definitive guidelines. In 2012, a reform of the basic physical training programme was introduced, including more rigorous daily, weekly and monthly training and evaluation, using standardised guidelines and goals. Additionally, the modified PFT was implemented in 2012. It is unknown whether basic physical training programmes with clearer guidelines and goals affect the risk of MS and which components of MS are affected in military services. This study aimed to conduct a longitudinal follow-up study to determine whether the reform of the basic physical training programme affected MS and its contributory factors.

\section{METHODS}

This retrospective study was approved by the Institutional Review Board (TSGHIRB No. 1-105-05104). All authors have completed the disclosure 


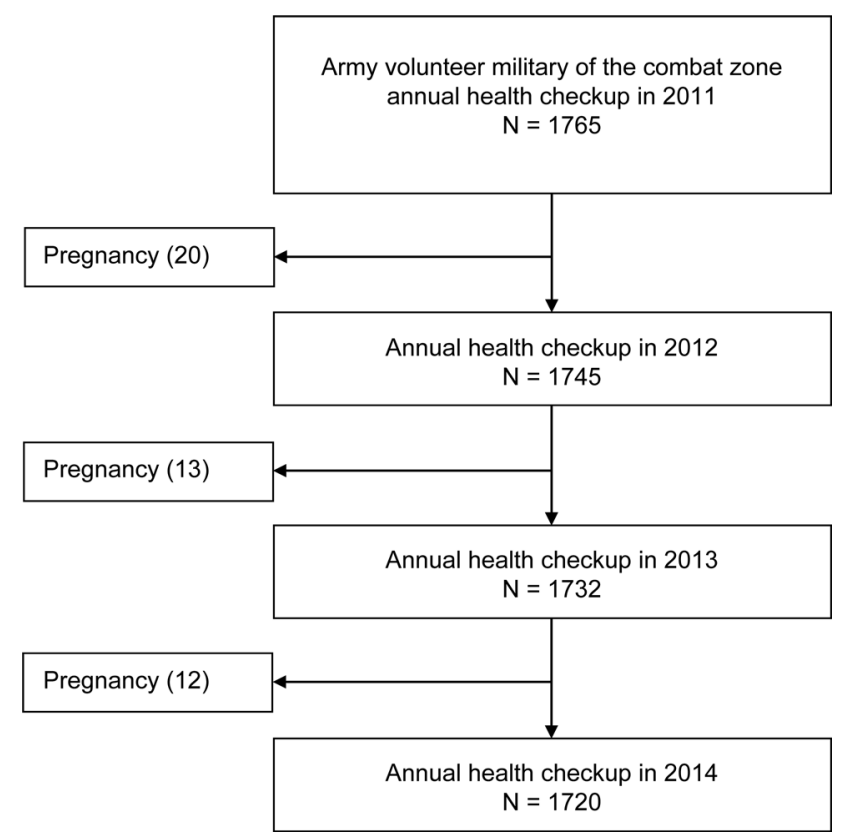

Figure 1 Study design. Volunteer soldiers completed the annual health check-up and the physical fitness tests in 2011, participated in the modified physical fitness programme, received annual health checkup results and were tested using the modified test standards from 2012 to 2014

form and declare that no support, financial or otherwise, has been received from any organisation that may have an interest in the submitted work, and there are no other relationships or activities that could appear to have influenced the submitted work.

\section{Participants}

Figure 1 shows the participant recruitment scheme. Electronic record data excluding personal identifying information were obtained from the military health examination databank. The volunteer soldiers who completed the annual physical examination from 2011 to 2014 and those who adopted the training and fitness testing under the 2012 reformed physical fitness programme were included. Candidates who became pregnant during the study or within 4 years of follow-up were excluded.

\section{Outcome measurements and health indices}

From 2011 to 2014, annual health examinations were performed on volunteer soldiers before the PFT. All clinical measurements were conducted in the morning after at least 8 hours of fasting. Waist circumference (WC) was measured at the umbilicus level using a plastic anthropometric tape, and blood pressure (BP) was measured using an automated sphygmomanometer. Blood samples were taken from all study participants between 08:00 and 10:00 hours after at least 8 hours of overnight fasting. Fasting blood samples were obtained by venepuncture, and the levels of serum triglycerides (TG), high-density lipoprotein cholesterol (HDL-C) and plasma glucose were assayed at a certified laboratory using automated techniques.

The study participants were diagnosed as having MS if they had three or more of the following five risk factors, based on the International Diabetes Federation guidelines. ${ }^{9}$

1. WC (South Asians): $\geq 90 \mathrm{~cm}$ (men) and $\geq 80 \mathrm{~cm}$ (women).

2. TG: $\geq 150 \mathrm{mg} / \mathrm{dL}$.

3. HDL-C): $<40 \mathrm{mg} / \mathrm{dL}$ (men) and $<50 \mathrm{mg} / \mathrm{dL}$ (women)
4. BP: systolic BP (SBP) $\geq 130 \mathrm{~mm} \mathrm{Hg}$ or diastolic $\mathrm{BP} \geq 85 \mathrm{~mm}$ $\mathrm{Hg}$ or treatment of previously diagnosed hypertension.

5. Fasting plasma glucose $\geq 100 \mathrm{mg} / \mathrm{dL}$ or previous diagnosis of type 2 diabetes mellitus.

\section{Intervention}

Before 2012, the basic physical fitness involved autonomous training with no definite guidelines, and the annual PFT included $3 \mathrm{~km}$ of running, $1 \mathrm{~min}$ of push-ups and $1 \mathrm{~min}$ of sit-ups. Mandatory training involved an estimated 18 MET-hours/week. After 2012, the reformed basic physical fitness training programme involved two times a day performance (morning and evening 06:00 to $07: 00$ hours and $16: 30$ to $18: 30$ hours, respectively), at least 3-5 times weekly as a group. Every training session reached an exercise intensity of $\geq 8$ MET-hours/day. Sessions in the training programme included cardiorespiratory fitness $(4-4.5 \mathrm{~km}$ runs and four short distance $(100 \mathrm{~m})$ sprints), strength training (including 40 sit-ups and 40 push-ups) in uniform, lasting $60 \mathrm{~min}$ for every training session. The 2012 modified PFT included $3 \mathrm{~km}$ of running, $2 \mathrm{~min}$ of push-ups and $2 \mathrm{~min}$ of sit-ups. The $3 \mathrm{~km}$ run was performed outdoors under consistent weather conditions on a level, paved surface. Sit-ups were used as a measure of muscular endurance of the trunk and hip flexors. The participants started the sit-ups in a supine position with the knees at a $90^{\circ}$ angle while being held by a partner. The upper body was raised in a manner in which the elbow touched the opposite knee. Push-ups were used as a measure of muscular endurance of the arm, shoulder and chest. The participants began the push-ups with a straight body with the chest and cheek touching the floor. The upper body was then raised until the arms were straight. The maximum numbers of repetitions for sit-ups and push-ups in 2 min were measured. Monthly tests were performed in each unit and annually at a national testing centre. The physical test results at the national centre were recorded in the personal files of the military personnel. The passing criteria for the test were also restandardised; for example, a 23 -year-old male officer was required to complete the $3 \mathrm{~km}$ run in $14 \mathrm{~min}$ and $25 \mathrm{~s}$ (compared with $15 \mathrm{~min}$ and $20 \mathrm{~s}$ before 2012), to perform 50 push-ups in $2 \mathrm{~min}$ (32 push-ups in $1 \mathrm{~min}$ before 2012) and 42 sit-ups in $2 \mathrm{~min}$ (29 sit-ups in $1 \mathrm{~min}$ before 2012). ${ }^{10}$

\section{Statistical analysis}

MS and its components were compared before (2011) and after (2012-2014) the introduction of the 2012 physical fitness programme. The effects of the physical fitness programme on various risk factors of MS were assessed by employing a mixed-effects model and a multivariate generalised estimating equation (GEE) using performances in the PFT (as continuous variables) as independent variables. The MS components were explored using a mixed-effects model. ORs and 95\% CIs were estimated using the GEE to determine the association of PFT with the prevalence of MS and its components. Two-sided $p<0.05$ were considered significant. All of the covariates in the model were adjusted in the GEE and mixed-effects models. Covariates including age, sex, body mass index (BMI), alcohol intake and smoking were included in the analysis, considering their potential effects on MS as previously reported. ${ }^{11}$ Crude ORs were obtained, as well as adjusted ORs, in which covariates with a significant $\mathrm{p}$ value $(<0.05)$ were included in the final model. Analyses were conducted using SAS V.9.4 and SPSS V.23.0. 
Table 1 Generalised equation showing AORs and 95\% Cls for metabolic syndrome*

\begin{tabular}{|c|c|c|c|}
\hline Parameter & AOR & $95 \% \mathrm{Cl}$ & $P$ value \\
\hline Gender (men vs women) & 1.08 & 0.71 to 1.65 & 0.725 \\
\hline Age & 1.09 & 1.06 to 1.11 & $<0.001$ \\
\hline BMI & 1.55 & 1.48 to 1.61 & $<0.001$ \\
\hline 1 year after the programme & 0.74 & 0.62 to 0.89 & 0.002 \\
\hline 2 years after the programme & 0.62 & 0.52 to 0.75 & $<0.001$ \\
\hline 3 years after the programme & 0.63 & 0.52 to 0.77 & $<0.001$ \\
\hline \multicolumn{4}{|c|}{ Physical fitness test performance } \\
\hline Sit-ups (repetitions) & 0.99 & 0.96 to 1.02 & 0.651 \\
\hline Push-ups (repetitions) & 0.99 & 0.97 to 1.02 & 0.670 \\
\hline Running (km/hour) & 0.64 & 0.49 to 0.84 & $<0.001$ \\
\hline
\end{tabular}

Values were adjusted for smoking and alcohol drinking and mutually adjusted. *AORs and $95 \% \mathrm{Cls}$ are shown for metabolic syndrome after the physical fitness programme, comparing between the 2011 baseline results and the physical fitness test performance.

AOR, adjusted OR; ; BMI, body mass index.

\section{RESULTS}

Of the 1765 participants who underwent health examinations at an Armed Forces General Hospital, 45 women were excluded due to pregnancy during 2011-2014. The remaining 1720 participants were included in the final analyses (1462 men and 258 women). Online supplemental table 1 summarises the demographics of the participants selected in 2011. MS was diagnosed in 246 of the 1720 participants. The distribution of covariates into men/women for smoking, alcohol consumption, and the number of MS risk factors is shown in Table 1. In 2011, $32.6 \%, 33.6 \%, 18.5 \%$ and $15.3 \%$ had $0,1,2$ or $\geq 3$ factors, respectively. For women: $54.7 \%, 27.1 \%, 9.69 \%$ and $8.52 \%$ had $0,1,2$ or $\geq 3$ factors, respectively. Generally, a higher prevalence of elevated TG, high BP and high fasting plasma glucose was observed in male participants than in female participants. Male and female participants had a similar prevalence of larger WC (25.7\% in men and $26.4 \%$ in women). The initial prevalence of MS was 14.3\% in 2011 (Figure 2). The prevalence among men in the armed forces increased from $14.5 \%$ in the $30-39$-year-old group to $19.1 \%$ in the $40-49$-year-old group. Among women, it increased from $7.1 \%$ in the 30-39-year-old group to $25.0 \%$ in the 40-49-year-old group (Figure 3). Following the introduction of the reformed PFT, the prevalence of MS decreased

\section{Prevalence Rate of Metabolic syndrome}

$25.00 \%$

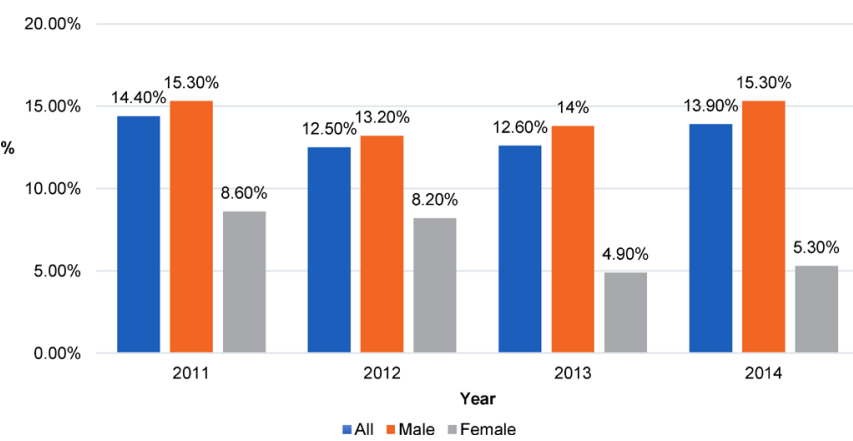

Figure 2 Prevalence of MS. The prevalence rate of MS was reduced in 2012 compared with that in 2011. Later on, such prevalence increased with age but generally remained lower than that in 2011. MS, metabolic syndrome.

\section{A \\ Prevalence Rate of Metabolic Syndrome}

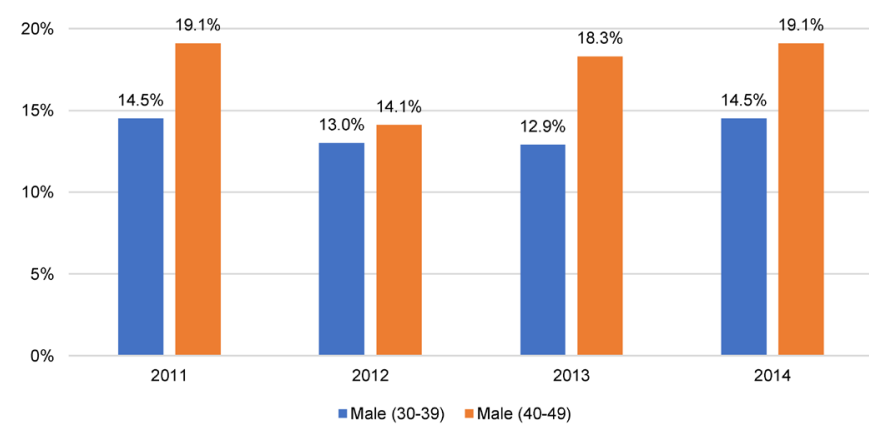

B

\section{Prevalence Rate of Metabolic Syndrome}

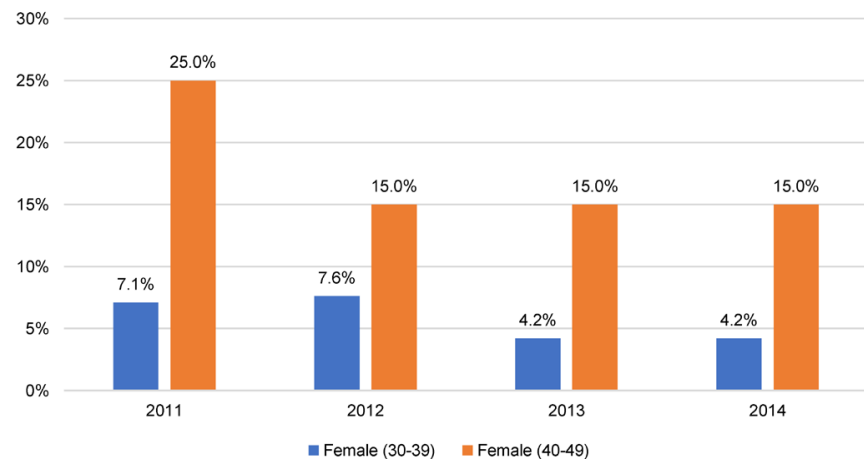

Figure 3 Age-specific prevalence of metabolic syndrome in (A) men and (B) women.

to $12.5 \%$. Subsequently, the prevalence of MS increased with age over time but generally remained lower than that in 2011. Considering the number of participants, the power of detecting two-tailed statistics with an alpha level of 0.05 , the statistical powers were estimated using McNemar's method for BP abnormality from $44.12 \%$ to $44.13 \%$, WC abnormality from $25.87 \%$ to $31.45 \%$, elevated fasting plasma glucose from $10.47 \%$ to $15.69 \%$, elevated TG from $20.93 \%$ to $24.59 \%$ and low HDL-C from $14.6 \%$ to $23.77 \%$ to be $0.8,0.99,0.99,0.96$ and 0.99 , respectively.

After the introduction of the reformed physical training programme in 2012, the ORs for MS were $0.743(95 \%$ CI, 0.617 to $0.894 ; \mathrm{p}=0.002), 0.626$ (95\% CI, 0.523 to $0.75 ; \mathrm{p}<0.001$ ) and 0.633 (95\% CI, 0.522 to $0.767 ; \mathrm{p}<0.001)$ in 2012,2013 and 2014, respectively (Table 1). In addition, running performance was negatively associated with the risk of MS (Table 2).

Table 2 shows the relationship between performance of PFT and individual components of MS, adjusting for age, sex and BMI. The running speed was negatively correlated to WC $(\beta=-0.42, p<0.001), T G(\beta=-11.37, p<0.001)$ and fasting glucose $(\beta=-0.54, p=0.054)$ and positively correlated with HDL-C $(\beta=2.14, p<0.001)$. The number of sit-ups in $2 \mathrm{~min}$ was negatively correlated with SBP $(\beta=-0.11, p=0.003)$, TG $(\beta=-0.41, p=0.048)$ and fasting glucose $(\beta=-0.07, p=0.003)$ and positively correlated with HDL $(B=0.16, p<0.001)$. The number of push-ups was negatively correlated to WC $(B=-0.05$, $\mathrm{p}<0.001)$.

\section{DISCUSSION}

This is the first study investigating the impact of introducing a physical training programme on the reduction of MS in military service. Additionally, performance in the annual tests was related 
Table 2 Effects of physical fitness performance on the components of metabolic syndrome with the use of the mixed-effects model

\begin{tabular}{|c|c|c|c|c|c|c|c|c|c|c|c|c|}
\hline \multirow[b]{2}{*}{ Variable } & \multicolumn{2}{|c|}{$\begin{array}{l}\text { Systolic blood } \\
\text { pressure }\end{array}$} & \multicolumn{2}{|c|}{$\begin{array}{l}\text { Diastolic blood } \\
\text { pressure }\end{array}$} & \multicolumn{2}{|c|}{ Waist circumference } & \multicolumn{2}{|c|}{ Triglycerides } & \multicolumn{2}{|c|}{ Fasting glucose } & \multicolumn{2}{|c|}{ HDL cholesterol } \\
\hline & B* $^{*}$ & $P$ value & $B^{*}$ & $P$ value & $B^{*}$ & $P$ value & $B^{*}$ & $P$ value & $B^{*}$ & $P$ value & $B^{*}$ & $P$ value \\
\hline \# of sit-ups in $2 \mathrm{~min}$ & -0.11 & 0.003 & -0.06 & 0.309 & -0.02 & 0.231 & -0.41 & 0.048 & -0.07 & 0.003 & 0.16 & $<0.001$ \\
\hline \# of push-ups in $2 \mathrm{~min}$ & 0.04 & 0.353 & 0.01 & 0.240 & -0.05 & $<0.001$ & -0.12 & 0.626 & -0.01 & 0.781 & 0.07 & 0.110 \\
\hline Running speed (km/hour) & -0.22 & 0.543 & -0.12 & 0.239 & -0.42 & $<0.001$ & -11.37 & $<0.001$ & -0.51 & 0.054 & 2.14 & $<0.001$ \\
\hline
\end{tabular}

*Adjusted for age, sex, smoking, alcohol drinking and body mass index (in 2011).

HDL, high-density lipoprotein.

to factors affecting MS, including SBP, WC, serum TG, fasting glucose and HDL.

Physical activity plays an important role in the aetiology and management of MS. ${ }^{12}$ While physical activity has long been regarded as an important component of a healthy lifestyle, poor cardiorespiratory fitness has been consistently associated with an increased risk of chronic diseases, including type 2 diabetes mellitus and cardiovascular disease. ${ }^{13}{ }^{14}$ Negative associations between cardiorespiratory fitness and MS prevalence have been reported. ${ }^{15-17}$ A study showed a 31\% reduction in MS prevalence among 105 adults after 20 weeks of aerobic physical training. ${ }^{18}$ Some studies using fitness exposure have demonstrated an inverse association with MS incidence, but the results of others using self-reported questionnaires have been ambiguous. ${ }^{19}$ In the 2012 physical fitness programme, every training activity achieved an exercise intensity of 8 MET-hours/day or greater and involved at least three training sessions per week. The total physical activity level was at least 24 MET-hours/week. To evaluate the effect of the reformed physical fitness programme, we used a retrospective cohort approach, instead of a cross-sectional method, to demonstrate the associations between physical fitness and MS. According to our analysis, compared with the baseline data, the risk of developing MS was reduced after introducing the physical fitness programme. The protective effect of the training was adjusted for possible confounders. Our findings indicate that the physical fitness programme substantially protected against MS and associated chronic conditions among military personnel.

Physical activity reduces cardiovascular disease risk, possibly because it improves the lipoprotein profile. ${ }^{20}$ Based on the American College of Sports Medicine recommendation, physical activities with higher intensity are associated with higher HDL-C levels and lower levels of total cholesterol and TG. ${ }^{21}$ Studies have reported an inverse association between cardiorespiratory fitness and MS incidence. ${ }^{22}$ In our study, after adjustment for covariates, BP declined after the introduction of the modified PFT, and the effect was maintained in the second and third years. Furthermore, HDL-C levels significantly increased after introducing the modified PFT, and the effect was sustained. Fasting glucose levels decreased in the second and third years after the introduction.

Physical activities, such as running, correlate more strongly with the prevalence of diabetes, hypertension and hypercholesterolemia. ${ }^{23}$ Muscular fitness has been shown to be inversely associated with WC, TG and fasting glucose. ${ }^{24} 25$ We showed that running performance was negatively correlated with the incidence of MS, WC, TG and fasting glucose and positively correlated with HDL level. The performance of sit-ups and push-ups in 2 min was negatively correlated with SBP, TG and fasting glucose and positively correlated with HDL level.

However, our study had some limitations. First, there was no information on personal dietary habits, including dining out. Although the food in the military was supplied by the
Non-staple Food Supply Station, externally supplied food eaten by the participants was not taken into consideration. Second, subgroup analyses in women were underpowered because of their small numbers. Hence, the effects of physical fitness on women require further investigation. Third, there was no adjustment for potential confounders, such as mental illness (eg, work stress, depression or post-traumatic stress disorder). The mental condition was not included in the regular physical record. However, milder conditions did not affect PFT receipt, and those with more severe conditions requiring regular medical attention were excluded from the study. Fourth, information on leisure-time physical activities, such as sports club participation or other activities, was not included. However, it is less likely that when the PFT requirement was introduced, the soldiers were involved in more leisure-time physical activities in addition to more rigorous training. Rather, a reduction in leisuretime activities may have been more probable. If so, the effect of the PFT might have been in favour of the null hypothesis. Data on these factors are needed to further evaluate the influence of physical fitness on MS in the future.

\section{CONCLUSION}

Our study revealed that the reformed physical fitness programme and the stricter eligibility criteria of the PFT were inversely associated with MS incidence among personnel in the armed forces. Better physical fitness performance can protect against MS and associated conditions. Clinicians should encourage sedentary military personnel to be more physically active to improve their physical fitness and reduce the risk of MS development.

Contributors This study was designed, directed and coordinated by Che-Fu Chang and Yue-Liang Guo, as the principal investigator, provided conceptual and technical guidance for all aspects of the project. Ching-Huang Lai and Che-Fu Chang performed and analysed the data. Yi-Chang Wu and Po-Chung Chen suggested and commented on the design of the study. The manuscript was written by Che-Fu Chang and Yue-Liang Guo and started on by all authors.

Funding The authors have not declared a specific grant for this research from any funding agency in the public, commercial or not-for-profit sectors.

\section{Competing interests None declared.}

\section{Patient consent for publication Not required.}

Ethics approval All procedures performed in studies involving human participants were in accordance with the ethical standards of the institutional research committee and with the 1964 Helsinki declaration and its later amendments or comparable ethical standards. The study was approved by the Institutional Review Board of the Tri-Service General Hospital (TSGHIRB No.: 1-105-05-104).

Provenance and peer review Not commissioned; externally peer reviewed.

Data availability statement Data may be obtained from a third party and are not publicly available. Data are obtained from a repository and are not publicly available.

Supplemental material This content has been supplied by the author(s). It has not been vetted by BMJ Publishing Group Limited (BMJ) and may not have been peer-reviewed. Any opinions or recommendations discussed are solely those of the author(s) and are not endorsed by BMJ. BMJ disclaims all 
liability and responsibility arising from any reliance placed on the content. Where the content includes any translated material, BMJ does not warrant the accuracy and reliability of the translations (including but not limited to local regulations, clinical guidelines, terminology, drug names and drug dosages), and is not responsible for any error and/or omissions arising from translation and adaptation or otherwise.

Open access This is an open access article distributed in accordance with the Creative Commons Attribution Non Commercial (CC BY-NC 4.0) license, which permits others to distribute, remix, adapt, build upon this work non-commercially, and license their derivative works on different terms, provided the original work is properly cited, appropriate credit is given, any changes made indicated, and the use is non-commercial. See: http://creativecommons.org/licenses/by-nc/4.0/.

\section{REFERENCES}

1 Reaven GM. Role of insulin resistance in human disease. Diabetes 1988;37:1595-607

2 Alberti K, Definition ZPF. Diagnosis and classification of diabetes mellitus and its complications. Part 1: diagnosis and classification of diabetes mellitus. Provisional report of a WHO consultation. Diabet Med 1998;15:539-53.

3 Parastouei K, Saeidipoor S, Sepandi M. Effects of symbiotic supplementation on the components of metabolic syndrome in military personnel: a double-blind randomised controlled trial. BMJ Mil Health 2020.

4 Expert panel on detection, evaluation, and treatment of high blood cholesterol in adults. executive summary of the third report of the National cholesterol education program (NCEP) expert panel on detection, evaluation, and treatment of high blood cholesterol in adults (adult treatment panel III). Jama 2001;285:2486.

5 Cortez AC, Rosa LBV, dos Santos MAP. Effects of sedentary behavior in metabolic syndrome and its components in adults: a systematic review. Int J Adv Res Sci Eng Technol 2019;6

6 Xu F, Cohen SA, Lofgren IE. The association between physical activity and metabolic syndrome in older adults with obesity. J Frailty Aging 2019;8:27-32.

7 Baygi F, Herttua K, Jensen OC. Global prevalence of cardiometabolic risk factors in the military population: a systematic review and meta-analysis. BMC Endocr Disord 2020;20:8.

8 Pihlainen K, Vaara J, Ojanen T. Effects of baseline fitness and BMI levels on changes in physical fitness during military service. J Sci Med Sport2020;23.

9 Grundy SM, Brewer HB, Cleeman JI. Definition of metabolic syndrome report of the National heart, lung, and blood Institute/American heart association conference on scientific issues related to definition. Circulation 2004;109:433-8.
10 Taiwan Ministry of National Defense. The reference book of basic physical fitness and swimming training for the armed forces, 2012. Available: 140.130.132.127/strong/ html/rules/rules_13.pdf [Accessed 12 Dec 2011].

11 Carnethon MR, Loria CM, Hill JO. Risk factors for the metabolic syndrome: the coronary artery risk development in young adults (cardia) study, 1985-2001. Diabetes Care 2004;27:2707-15.

12 Segura-Jiménez V, Parrilla-Moreno F, Fernández-Santos JR. Physical fitness as a mediator between objectively measured physical activity and clustered metabolic syndrome in children and adolescents: The UP\&DOWN study. Nutr Metab Cardiovasc Dis 2016;26:1011-9.

13 Ö E, Ekblom-Bak E, Rosengren A. Cardiorespiratory fitness, sedentary behaviour and physical activity are independently associated with the metabolic syndrome, results from the SCAPIS pilot study. PloS One 2015;10:e0131586.

14 Fagard RH. Exercise characteristics and the blood pressure response to dynamic physical training. Med Sci Sports Exerc 2001;33:S484-92.

15 Lakka TA, Laaksonen DE, Lakka HM. Sedentary lifestyle, poor cardiorespiratory fitness, and the metabolic syndrome. Med Sci Sports Exerc 2003;35:1279-86.

16 Jurca R, Lamonte MJ, Church TS. Associations of muscle strength and aerobic fitness with metabolic syndrome in men. Med Sci Sports Exerc 2004;36:1301-7.

17 Farrell SW, Cheng YJ, Blair SN. Prevalence of the metabolic syndrome across cardiorespiratory fitness levels in women. Obes Res 2004;12:824-30.

18 Katzmarzyk PT, Leon AS, Wilmore JH. Targeting the metabolic syndrome with exercise: evidence from the heritage family study. Med Sci Sports Exerc 2003;35:1703-9.

19 Van den Heuvel SG, Boshuizen HC, Hildebrandt VH. Effect of sporting activity on absenteeism in a working population. Br J Sports Med 2005;39:e15.

20 Kraus WE, Houmard JA, Duscha BD. Effects of the amount and intensity of exercise on plasma lipoproteins. N Engl J Med 2002;347:1483-92.

21 Garber CE, Blissmer B, Deschenes MR. American College of sports medicine. American College of sports medicine position stand. quantity and quality of exercise for developing and maintaining cardiorespiratory, musculoskeletal, and neuromotor fitness in apparently healthy adults: guidance for prescribing exercise. Med Sci Sports Exerc2011;43:1334-59.

22 Carnethon MR, Gidding SS, Nehgme R. Cardiorespiratory fitness in young adulthood and the development of cardiovascular disease risk factors. JAMA 2003;290:3092-100.

23 Burger SC, Bertram SR, Stewart RI. Assessment of the 2, $4 \mathrm{Km}$ run as a predictor of aerobic capacity. S Afr Med J 1990;78:327-9.

24 Williams PT, Franklin B. Vigorous exercise and diabetic, hypertensive, and hypercholesterolemia medication use. Med Sci Sports Exerc 2007;39:1933-41.

25 KJ K, Kang SJ, Lee KS. Association between cardiorespiratory, muscular fitness and metabolic syndrome in Korean men. Diabetes Metab Syndr 2018;13:536-41. 